\title{
MODALIDADES DA TECNOLOGIA E SUAS CONSEQUÊNCIAS CULTURAIS
}

\author{
Alberto Cupani ${ }^{1}$
}

\begin{abstract}
Resumo:
Conforme uma distinção já habitual, a tecnologia existe em quatro modalidades: como artefatos e sistemas, como certo tipo de conhecimentos, como atividades específicas e como determinada atitude humana perante a realidade, natural ou social. Em conjunto, elas configuram nosso mundo, o mundo tecnológico. Continuando com uma análise começada em outro trabalho, exploro aqui essas modalidades no que tange às consequências que a sua proliferação tem para a cultura e a educação. Destaco efeitos como a universalização das normas e critérios técnicos, a preferência pelo artificial, a transformação da inteligência em processamento de informação e, sobretudo, o nivelamento das aspirações humanas, apontando alguns interrogantes abertos à educação.
\end{abstract}

Palavras-chave: Modalidades da tecnologia. Tecnologia como cultura. Tecnologia e educação.

\section{MODALIDADES DE TECNOLOGÍA Y SUS CONSECUENCIAS CULTURALES}

\section{Resumen:}

De acuerdo conuna distinción ya habitual, la tecnología existe en cuatro modalidades: como artefactos y sistemas, como cierto tipo de conocimientos, como actividades específicas y como determinada actitud ante la realidad, natural o social. En conjunto, ellas configuran nuestro mundo, el mundo tecnológico. Continuando un análisis comenzado en otro trabajo, exploro aquí esas modalidades en lo que respecta a las consecuencias que su proliferación tiene para la cultura y la educación. Destaco efectos como la universalización de las normas y criterios técnicos, la preferencia por lo artificial, la transformación de la inteligencia en procesamiento de información y, sobre todo, la nivelación de las aspiraciones humanas, apuntando algunos interrogantes abiertos a la educación.

Palabras-clave: Modalidades de la tecnología. Tecnología y cultura. Tecnología y educación.

É quase desnecessário observar que nosso mundo, sobretudo o urbano, é crescentemente tecnológico. Rara é a atividade que, hoje em dia, é realizada sem o auxílio de alguma tecnologia, seja ao trabalhar, nos comunicarmos, nos deslocarmos ou nos entretermos.

A tecnologia é uma realidade complexa, que tenho analisado em (CUPANI, 2009). Seguindo uma distinção já clássica de C. Mitcham (MITCHAM, 1994), deve-se distinguir quatro modalidades de existência da tecnologia. Com efeito, ela se nos apresenta na forma de artefatos (e sistemas), de certo tipo de conhecimento, de determinadas atividades, e de uma específica atitude humana diante da realidade.

A presença da tecnologia como artefatos e sistemas é a sua modalidade mais óbvia e mais frequentemente evocada. Os computadores e os telefones celulares, ligados

\footnotetext{
${ }^{1}$ Doutor em Filosofia, professor titula aposentado do Departamento de Filosofia da Universidade Federal de Santa Catarina. E-mail: cupani.alberto@gmail.com.
} 
pela internet; as luminárias de diversos tipos alimentadas pelas instalações elétricas; os trens e aeroplanos que percorrem trilhos e rotas aéreas, servidos por complexas redes de monitoramento; as maquinarias, cada vez mais automatizadas, que possibilitam a produção industrial e os telescópios, cíclotrons e satélites, interligados por sofisticadas conexões aos centros de pesquisa, são alguns exemplos deste mais ostensivo modo da tecnologia.

No entanto, a tecnologia não consiste apenas em suas concreções materiais ou energéticas. Existe um conhecimento especificamente tecnológico, diferente do saber científico (CUPANI, 2017, cap. 7). Reparar na existência desse conhecimento exige superar a noção de que a tecnologia consista apenas na aplicação da ciência, embora parcialmente ela o seja. Não resta dúvida de que certas produções tecnológicas resultaram da aplicação de conhecimentos científicos: valha a bomba atômica como exemplo, ou, mais próxima e benignamente, a produção de remédios a partir da química e da biologia. No entanto, reduzir a tecnologia a ciência (moderna) aplicada torna inexplicáveis grandes realizações de povos antigos (pirâmides, aquedutos, catedrais), e esquece inventos que precederam teorias científicas (como o caso da máquina de vapor com relação à termodinâmica), ou inventores de tecnologias que não foram cientistas (como Thomas A. Edison). ${ }^{2}$ Ocorre que, ao passo que o conhecimento científico é abstrato e geral, as produções tecnológicas são sempre concretas. Além do mais, a tecnologia consiste na produção de algo novo, não na compreensão de algo existente (ela é conhecimento do que pode ser). Existe, sim, um conhecimento tecnológico que se expressa em conceitos próprios (como "switch", ou “otimizar"), que gera explicações e teorias típicas, ${ }^{3}$ que fornece regras em vez de identificar leis, e que têm seu centro de gravidade no "saber como", mais do que no "saber que".

A terceira modalidade da tecnologia consiste no conjunto de atividades em que ela também se manifesta: projetar (design), fabricar, operar, monitorar, manter, consertar e usar aparelhos e sistemas. A imensa maioria das pessoas são (somos) apenas usuários da tecnologia; muitos são operadores, monitores ou técnicos; um número mais reduzido são designers ou fabricantes. Em todo caso, ninguém escapa de executar ações

2 É, portanto, mais correto afirmar que a tecnologia consiste na aplicação sistemática da razão teórica a problemas detectados pela razão prática (FERRÉ, 1995, cap. 4).

3 Explicar o funcionamento de um motor, p.e., não consiste em apontar a relação física ou química entre seus componentes. Uma teoria sobre o voo de aeronaves não é científica, mas tecnológica.

\begin{tabular}{|l|l|l|l|l|}
\hline Ronista Pialectus & Ano 9 & n. 17 & Maio - Agosto 2020 & p.82-95 \\
\hline
\end{tabular}


possibilitadas, facilitadas ou exigidas pela tecnologia. ${ }^{4}$ Mais ainda: as tecnologias "moldam" e mudam o significado das atividades humanas: "viajar" significa quase sempre deslocar-se em algum veículo automotor; "comunicar-se" significa, cada vez mais, utilizar um telefone celular, assim como "escrever" significa servir-se de um processador de textos em um computador. "Educar", como veremos, não é uma exceção a essa regra.

E chegamos por fim à quarta modalidade da tecnologia: o seu caráter de específica atitude e mentalidade, uma certa "volição", como a denomina Mitcham ao sublinhar que consiste em uma determinada vontade humana com relação ao mundo (MITCHAM, 1994, cap. X). A tecnológica é uma atitude humana diferente de outras como a religiosa, a filosófica, a científica e a filosófica. ${ }^{5}$ Trata-se de uma disposição que "foca" a realidade, natural ou social, em termos do que pode ser feito com ela: recursos que levarão a um produto desejado. ${ }^{6}$ Visa o controle ou domínio do existente, bem como à sua superação. Inovar e inventar são as suas marcas, alcançando o antes apenas sonhado (como ao permitir-nos voar), ou o nem imaginado (como o cinema, ou a "realidade virtual"). Essa quarta modalidade da tecnologia é a mais difícil de perceber, pois constitui a atmosfera, por assim dizer, de boa parte da humanidade, principalmente dos habitantes das cidades. Como ocorre com tudo o que é habitual, em qualquer época, parece-nos "natural" não apenas usar fones e carros, mas esperar por novos artefatos que facilitem nossa vida e que diminuam o peso da existência... natural. Também, preferir procedimentos e recursos mais confortáveis, rápidos e eficientes, qualidades essas ("valores") que decorrem da mentalidade tecnológica.

A referência à tecnologia como atitude convida a compará-la com a técnica. Esta última palavra refere-se a procedimentos padronizados (técnicas) que permitem alcançar determinado resultado desejado de maneira metódica e econômica, sendo além do mais transmissíveis, isto é, podendo ser ensinados. Nesse sentido, existem técnicas para fabricar vasilhames, para tocar instrumentos, escrever, para cozinhar, e até para

4 Note-se que, embora em toda cultura existam indivíduos que dominam profissões (marceneiros, ferreiros, etc.), a sociedade tecnológica produz o técnico, o expert ou perito, cujo conhecimento e habilidade são distantes das capacidades do leigo. Este último dificilmente pode salvar essa distância, e depende totalmente do primeiro, ficando sua vida prejudicada quando algum artefato ou sistema falha.

5 A risco de simplificar, pode-se caracterizar a atitude religiosa pela reverência e a submissão ante o existente, a filosófica, pela admiração e a crítica, a científica pela curiosidade e o desejo de compreender, e a artística pela aspiração a expressar impressões, emoções, ideais.

6 "E o resto", como apontou cedo na história da Filosofia da Tecnologia o filósofo Mario Bunge (BUNGE, 1980, p. 199). Eis a origem, não apenas do lixo e a poluição (“externalidades”), mas também das dimensões humanas não desenvolvidas por uma educação excessivamente tecnológica.

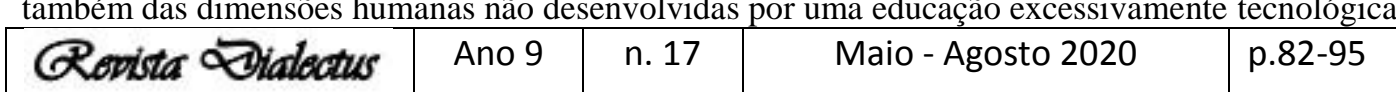


dançar: existem técnicas corporais (amassar) e intelectuais (calcular). ${ }^{7}$ Toda técnica é um saber-fazer, não necessariamente expresso em forma de um conhecimento abstrato. A invenção de técnicas é caraterística do homem (e, muito reduzidamente, de outros animais), em seu desejo de viver melhor, como teorizou faz tempo o filósofo José Ortega y Gasset (ORTEGA Y GASSET, 1965). O produto de uma técnica é o arte-fato (algo feito com arte, ou tekhne). ${ }^{8}$ A tecnologia diferencia-se da (mera) técnica por estar sustentada por um saber teórico (modernamente, a ciência) que a cria ou aprimora (v. FERRÉ,1995). No entanto, a dificuldade de estabelecer limites precisos entre técnica e tecnologia explica que diversos autores usem um desses termos ou o outro para designar, em geral, essa dimensão da vida humana.

Por outra parte, afirmar que nossa vida transcorre entre artefatos tecnológicos pode suscitar alguma dúvida. Todo mundo admite que um microscópio, um drone ou um refrigerador são artefatos tecnológicos. Mas, que dizer de um par de óculos, um vestido adquirido já pronto ou simples lápis? Embora não paremos para pensar, eles são também testemunhas da presença da tecnologia, pois foram fabricados em série em fábricas (instalações tecnológicas) cada vez mais automatizadas. São produtos da tecnologia, como de resto a imensa maioria dos objetos de que precisamos hoje em dia. ${ }^{9}$ Por outra parte, os artefatos têm diferentes presenças em nossa vida, que foram estudadas pelo filósofo Donald Ihde (IHDE, 2017, cap. 5). Existem tecnologias que incorporamos (como nossos óculos, sobretudo os de contato, ou a nossa bicicleta), tornando-se quase transparentes: percebemos o mundo ao agirmos ajudados por elas. Outras tecnologias têm um papel hermenêutico (como um termómetro ou um GPS): mediante elas, interpretamos o mundo. Em terceiro lugar estão as tecnologias percebidas como se fossem algo autônomo, dos relógios até aos robôs. Existem, por fim, tecnologias que agem como pano de fundo de nossa existência, a começar pela iluminação elétrica, o ar condicionado e a internet. Em todos esses casos, e conforme sua especificidade, as tecnologias revestem-se de certa "presença ausente" (Ihde), pois normalmente não prestamos atenção às mesmas, a não ser quando falham. Essa

7 Desde Aristóteles, costuma-se distinguir entre técnicas de produção (de algo externo ao sujeito, como escrever) e técnicas de desempenho (algo inerente ao sujeito, como dançar). A Filosofia da Tecnologia (ou da Técnica) foca principalmente a capacidade de produzir.

8 A palavra grega tekhne (ars em latim) designava já esse proceder embasado em certo conhecimento. É mais raro usar-se "técnica" para designar o artefato (vasilhame, comida, texto, música, dança).

9 No caso dos óculos, eles não seriam possíveis sem os conhecimentos científicos (óptica e fisiologia humana) que os possibilitaram. A vestimenta em série supõe cálculos estatísticos de medidas-médias para estabelecer os "talhes". Assim vistos, são artefatos tecnológicos por direito próprio.

\begin{tabular}{|l|l|l|l|l|}
\hline Revista Wialectus & Ano 9 & n. 17 & Maio - Agosto 2020 & p.82-95 \\
\hline
\end{tabular}


presença ausente explica que o mundo tecnológico (entendendo por ele a totalidade dos sistemas de artefatos existentes) não provoque estranheza, e o vivamos como "o mundo", sem mais nem menos. No entanto, tudo quanto fazemos está hoje mediado pela tecnologia, em suas diversas modalidades. Conforme as situações, uma das modalidades é mais relevante do que as outras. ${ }^{10}$

Em (CUPANI, 2017, cap.8) apontei diferentes impactos que a introdução da tecnologia produz nas culturas. Amplio aqui a análise de alguns desses impactos, mencionando outros ainda não tratados naquela obra, a começar pela observação de que, em uma sociedade tecnológica, os meios importam mais do que os fins. Em uma tal sociedade, escrevi "todas as tarefas e dificuldades são, aos poucos, interpretadas como problemas técnicos, ou seja, como questões que podem ser resolvidas pelas escolhas dos meios apropriados para um objetivo proposto" (CUPANI, 2017, p.188). Ocorre que os problemas com que nos deparamos são de muito diversa índole. Enfrentamo-nos com problemas técnicos/tecnológicos, mas também com problemas éticos, políticos, científicos, filosóficos, religiosos, existenciais, ecológicos, bélicos, sociais, terapêuticos, pedagógicos... Como reduzi-los a um único padrão? A mentalidade tecnológica, entretanto, nos estimula a crer que todos eles podem ser transformados em problemas bem definidos, aos que corresponde uma maneira preferencial de resolução, que será alcançada se formos suficientemente persistentes. Esse é, precisamente, o perfil de um problema técnico, já se trate de melhorar o desempenho de um veículo, aprimorar a receita de uma refeição ou calcular a trajetória de um foguete. ${ }^{11} \mathrm{E}$, geralmente, a escolha do meio apropriado significa a utilização do recurso tecnológico mais avançado: um espremedor de frutas elétrico, uma máquina de lavar roupas automática, um projetor Datashow... A atenção quase exclusiva aos meios faz com que não sejam discutidos os fins das atividades nem o porquê das mesmas, ${ }^{12}$ e consagra a obediência ao perito, seja

10 Cabe não esquecer que me refiro aos habitantes do mundo "civilizado", especialmente aos habitantes das suas cidades, e não a toda a humanidade. Moradores de regiões desérticas ou florestas vivem, sabidamente, uma vida pré-tecnológica, embora não carente de técnicas e "alcançada" paulatinamente pelas redes tecnológicas mundiais (de comunicação, transporte, comércio e guerra).

11 Por isso mesmo, os problemas técnicos (ou reduzidos a tais) parecem "simples" frente à complexidade de uma questão não técnica (Como lidar com o tráfico de drogas? Como defender as espécies ameaçadas? Como dar um sentido à minha vida?)

12 Trata-se do exercício da (mera) "racionalidade instrumental", detectada pelos filósofos da Escola de Frankfurt (Adorno, Horkheimer) na década de 1940.

\begin{tabular}{|l|l|l|l|l|}
\hline Q Povista Dialectus & Ano 9 & n. 17 & Maio - Agosto 2020 & p.82-95 \\
\hline
\end{tabular}


ele um técnico em informática, um mecânico de automóveis, um médico ou um cientista. No âmbito da educação, isso conduz a manter práticas pedagógicas que visivelmente já não mais se harmonizam com o tipo de sociedade em que vivemos (o ensino-aprendizagem tradicional, praticado em escolas com currículos definidos).

Ao destaque dos meios associa-se o que denominei "universalização das normas técnicas", isto é, que as normas que guiam implicitamente a ação instrumental tornam-se valores sociais: a racionalidade (adequação de meios a fins e programação lógica dos passos de um processo), ${ }^{13}$ a eficiência (alcançar o fim desejado da maneira mais econômica), a planificação e a exatidão (condição da eficiência), a quantificação, que facilita o controle dos objetos, processos e situações, bem como a rapidez (economia de tempo). Em conjunto, esses valores configuram o propósito da mentalidade tecnológica, que visa o controle e a determinação da realidade, natural ou social (CUPANI, 2017, p. 189-190). Na educação, leva, p.e., à introdução de tecnologias (uso de tablets, pesquisa mediante o celular, teleconferências) para melhorar o ensino, sem refletir sobre a natureza deste último e sua adequação a uma realidade constantemente revolucionada pela própria tecnologia. Não se percebe, por exemplo, que a educação está cada vez mais "enviesada" pelo uso de tais recursos e pelo acúmulo de informação difícil de organizar. O conhecimento, aliás, está cada vez mais identificado com esse acúmulo de informação. A educação assim tecnologizada não equivale a educação tecnológica (diferente da educação científica), nem àquela cultura tecnológica que o filósofo (e engenheiro) G. Simondon pregava como necessária (SIMONDON, 1989). ${ }^{14}$

Outro aspecto destacado do mundo tecnológico é a grande valoração do artificial, que em outras sociedades, ou não é visto como algo diferente ao natural, ou é reconhecido, porém olhado com desconfiança ou desinteresse. Escrevi a respeito:

Isso se percebe no entusiasmo (ou ao menos, a complacência) com que são acolhidos os novos artefatos, as máquinas, os procedimentos técnicos e os materiais insólitos, seja no lar, na indústria ou na administração (para não falar do âmbito militar). Combina-se nessa confiada aceitação o alívio de tarefas penosas e a abertura a novas possibilidades de ação ou de experiência, a melhor utilização do tempo e a maior produtividade (CUPANI, 2017, p.191).

13 Ou seja, um algoritmo, essência da "inteligência artificial".

14 Para Simondon (1924 - 1989), uma iniciação na cultura tecnológica, isto é, no conhecimento dos princípios de funcionamento das máquinas, devia fazer parte de uma educação humanizadora.

\begin{tabular}{|c|c|c|c|c|}
\hline Revista Q Dialectus & Ano 9 & n. 17 & Maio - Agosto 2020 & p.82-95 \\
\hline
\end{tabular}


Gostaria aqui de acrescentar que, dessa maneira, perde-se ou abandona-se a noção do natural como parâmetro da vida humana, particularmente da educação, parâmetro esse reivindicado diversas vezes na história do pensamento pedagógico (basta lembrar Rousseau). ${ }^{15}$ Esse abandono acentua-se devido às diversas maneiras em que a índole biológica do homem é ou pode ser alterada (próteses de diversos tipos, prolongamento artificial da vida ou da aparência de juventude, engenharia genética) e à produção de robôs, especialmente os humanoides, fenômenos esses que questionam a noção (e a existência) de uma natureza especificamente humana. Esse questionamento, que atinge em cheio o âmbito da ética, afeta também a educação, voltada tradicionalmente a "formar" os indivíduos conforme o que se considera propriamente humano. Retomarei o assunto mais adiante.

Um aspecto particularmente relevante da noção tradicional da natureza humana consiste na caracterização da inteligência. A seu desenvolvimento e aprimoramento está devotada boa parte da educação tradicional, para bem ou para mal. ${ }^{16}$ Entendida como a capacidade de resolver problemas teóricos ou práticos de maneira não instintiva, ela foi considerada por séculos como um dos atributos da humanidade. Mas hoje sabemos que a inteligência não é privativa do animal humano. Também, que, contra o que supomos vulgar e intuitivamente, ela não consiste algo que resida em nosso cérebro, mas em um relacionamento deste último com diversos apoios externos (CLARK, 2003). Nosso pensar e nosso agir inteligentes são possíveis graças aos artefatos que, desde os primórdios, os seres humanos foram produzindo: instrumentos, máquinas, suportes, códigos e objetos, do alfabeto ao computador, da faca ao automóvel. Os inventos tecnológicos são ao mesmo tempo produtos e estímulos do desenvolvimento da nossa inteligência. ${ }^{17}$

Por outro lado, na sociedade tecnológica o cérebro humano trata de ser compreendido por semelhança com o funcionamento do computador ("inteligência artificial"), e, de forma correlata, trata-se de conseguir que os computadores emulem e até superem as capacidades humanas. O último já está ocorrendo, por exemplo, em

15 Esse parâmetro inclui metáforas como as da cultura entendida como cultivo. Ironicamente, na sociedade industrializada a apresentação de um produto como natural tem muito apelo entre os clientes/usuários, sinal de que esse abandono é de algum modo experimentado como uma perda.

16 Como quando se identifica o cultivo da inteligência com determinada disciplina (tipicamente, as matemáticas), esquecendo outras formas de inteligência (como a corporal) e o estímulo de outras capacidades, como a imaginação ou a sensibilidade.

17 Quando lamentamos, com razão, a utilização constante e quase hipnótica dos celulares por nossos contemporâneos, podemos não advertir o quanto esse recurso está possibilitando novas e insólitas formas de inteligência, como ocorreu com tantos inventos do passado.

\begin{tabular}{|l|c|c|c|c|}
\hline Q Povista Dialectus & Ano 9 & n. 17 & Maio - Agosto 2020 & p.82-95 \\
\hline
\end{tabular}


matéria de cálculos e no processamento de dados, e tem pensadores que preveem e temem o advento de uma superinteligência (a "singularidade") que subjugue o ser humano (BOSTROM, 2018). A própria noção de uma inteligência artificial vem sendo criticada, há décadas, pelos filósofos. John Searle observou que a rigor os computadores não pensam (SEARLE, 1980); Hubert Dreyfus destacou o caráter corporal e intencional da inteligência humana (DREYFUSS, 1992), e Mario Bungecriticou o que denominou "computacionalismo", convencido de que a verdadeira compreensão do funcionamento do cérebro irá surgir da neurofisiologia e da filosofia da mente, e não da informática (BUNGE,2017). O advento da superinteligência é, certamente, algo discutível, mas os progressos da inteligência artificial (cada vez mais sistemas a utilizam) são patentes, a pesar da discussão filosófica. Em todo caso, estamos nos familiarizando com a ideia de uma tal inteligência, como pode ser constatado pelo uso frequente de expressões como "programar-se" para uma tarefa, ou "acessar" informação da nossa memória. A inteligência artificial é usada cada vez mais para monitorar as nossas vidas, transformando-nos em objetos controláveis e manipuláveis. Programas que armazenam dados sobre nossa identidade e nossa vida cotidiana nos vigiam e nos induzem a pensar de certa maneira, a desejar ou temer coisas, a comprar e até a votar. ${ }^{18}$ Em resumo: é de se temer que a nossa inteligência, como pessoas, se converta cada vez mais em inteligência de máquina, e que sejamos mais "inteligentes", mas que as decisões não sejam propriamente nossas. Sem chegarmos a esse extremo, vale a pena lembrar, sobretudo no âmbito da educação, que toda tecnologia condiciona nossas escolhas ${ }^{19}$ : nenhuma nos torna absolutamente livres, sendo reciprocamente um importante problema ético e pedagógico o da possível liberdade nossa com relação à tecnologia, em geral.

Os artefatos tecnológicos tendem a ser cada vez mais autônomos. Basta o estímulo da nossa vizinhança, e portas automáticas abrem-se e fecham-se. Os caixas bancários precisam apenas da inserção do cartão e a senha: o restante do procedimento é por conta deles. O computador e o celular esperam por nossas ordens para nos comunicar, para nos ensinar, para nos entreter. Máquinas derrotam faz tempo jogadores de xadrez. Existem bichinhos artificiais que brincam com as crianças, e robôs que

18 Esse bombardeio constante de estímulos (alertas, convites, tentações, ordens disfarçadas de conselhos) tende a constituir uma sorte de superego coletivo. A sua transgressão provoca um vago mal-estar.

19 Especialmente, quando o programa de computador, p.e., nos impõe alternativas de escolha, frente ás quais não temos chance de inovar.

\begin{tabular}{|l|l|l|l|l|}
\hline Q Povista Dialectus & Ano 9 & n. 17 & Maio - Agosto 2020 & p.82-95 \\
\hline
\end{tabular}


podem cuidar de idosos e pessoas descapacitadas. As pessoas se afeiçoam a eles e com eles dialogam. ${ }^{20}$ Cada vez mais, aceitamos sem surpresa esses elementos do mundo que não surgiram da Natureza, enquanto esta última se torna para o cidadão comum menos compreensível que para o homem "primitivo": o homem contemporâneo confia na ciência para alcançar essa compreensão e na tecnologia para saber como (sobre)viver.

Por mais significativas que sejam as consequências anteriormente descritas, a mais importante, se formos acreditar em críticos como Neil Postman (POSTMAN, 1993), consiste em que o reinado da tecnologia ("tecnopólio", segundo o autor) torna cada vez mais difícil imaginar uma vida diferente, individual e social. Isso porque as pessoas vão desenvolvendo aos poucos o que outros autores denominam um "ego tecnológico" que tende a dominar o restante da personalidade. Trata-se do traço de caráter que incorpora, em forma cada vez mais radical, a modalidade da tecnologia que apresentei como atitude e mentalidade, cujo propósito é o controle da realidade. No indivíduo, traduz-se pela submissão das outras capacidades humanas ao afã de eficiência, decorrente por sua vez da especialização e a planificação. Tudo quanto é espontâneo é submetido a cálculo e método; a experiência, cada vez mais mediatizada por artefatos, torna-se como que impessoal. ${ }^{21}$ A capacidade de juízo (pessoal) perde valor diante da autoridade atribuída a critérios ou informações técnicas. A capacidade de agir (agency) em sentido propriamente humano, vale dizer como um ser indagador, crítico, capaz de optar e criativo, vê-se diminuída por uma civilização em que as metas e os caminhos parecem estar definidos de antemão. ${ }^{22} \mathrm{~A}$ tecnologia des-carrega o homem do peso de certas tarefas e o exime de certas habilidades (não precisa saber cavalgar para se deslocar rapidamente), porém o obriga a adquirir outras habilidades (como saber lidar, às vezes inesperadamente, com artefatos novos), e manter o exercício delas amiúde ao preço de certo grau de stress. O benefício que o homem crê perceber no universo tecnológico parece explicar a sorte de cumplicidade com que aceita a tecnologia. O ser humano é capaz de se interrogar sobre si mesmo e seu destino ("ser ou não ser"), porém corre o risco, na sociedade tecnológica, de nada perguntar-se, pois fica como que descentrado, dissipado, distraído de si mesmo. Ao mesmo tempo, e pela

20 Mas também podem teme-los. Margaret Boden (BODEN, 2018) observa que a semelhança não total com seres humanos pode ser inquietante. Também, que a reação humana ante esses artefatos depende da cultura (os japoneses parecem aceita-los mais facilmente do que os ocidentais).

21 Os artefatos, ainda que permitindo usos pessoais, possibilitam o que em princípio qualquer um pode realizar.

22 Incluindo a noção (não nova, certamente) de que a tecnologia é sempre fator de progresso e nos conduz a um futuro melhor.

\begin{tabular}{|l|l|l|l|l|}
\hline Q Povista Dialectus & Ano 9 & n. 17 & Maio - Agosto 2020 & p.82-95 \\
\hline
\end{tabular}


mesma razão, torna-se um ser desenraizado do seu meio tradicional e mais sintonizado com o caráter abstrato e sistêmico do universo tecnológico, ao qual está "entregue", pois na imensa maioria dos casos nem chega a compreender como ele funciona. ${ }^{23}$ Sabe, sim, “funcionar" cada vez mais dentro desse universo.

A premissa implícita de toda invenção tecnológica é a de que ela irá nos capacitar para determinada ação, previamente mais difícil (suponhamos, cavar, antes das retroescavadeiras) ou impossível (como substituir um coração defeituoso). Essa capacitação supõe, por sua vez, a promoção de uma vida melhor. Mas essa vida está, na sociedade tecnológica, de algum modo prefigurada e prevista como igual para todos. Não apenas o que seja saúde, segurança, lazer e bem-estar, mas até o que signifique ser feliz ou sentir-se realizado: a posse ou disponibilidade crescente de recursos tecnológicos há de ser a varinha mágica que nos faça viver bem, isto é, satisfeitos. Ocorre, porém, que o ser humano é irremediavelmente individual, e sua existência é, “em cada caso a minha" (M. Heidegger). Ou seja, que o que pode constituir a realização pessoal, o que pode fazer com que a vida tenha significado, não é reduzível a uma fórmula geral. Daí a relevância dos autores como Amartya Sen (SEN,2015) e Martha Nussbaum (NUSSBAUM,2013), que levantam a questão da necessidade de fazer das tecnologias instrumentos de capacitação humana para a vida que cada qual entenda como significativa. ${ }^{24}$ A educação, irremediavelmente mediada pela tecnologia, deveria promover a reflexão crítica sobre a mesma, sobre seu poder nivelador, ao mesmo tempo que conscientize sobre as novas possibilidades de ação, pensamento e emoção que a tecnologia oferece (BRONCANO, 2000). Essa reflexão é tanto ou mais importante do que a conscientização sobre os efeitos nocivos da produção tecnológica, como a poluição ambiental, o crescimento da letalidade das armas, o esgotamento dos recursos do planeta ou a ameaça à existência das espécies vivas.

Para tudo isso precisamos de uma nova noção de educação, entendida como formação (ou ao menos preparação) dos seres humanos, um desafio cada vez maior para

23 Sirvo-me para estas considerações, tal como em (CUPANI 2017), de autores como Winner (1977), Pacey (1994) e Borgmann (1984).

24 Sen e Nussbaum propõem suas ideias pensando nas pessoas carentes - econômica e culturalmente dos países e regiões subdesenvolvidas, porém (como eles mesmos reconhecem) também os países abastados têm setores de população carente. Por isso, sua teoria é válida como relativa ao papel da tecnologia em geral.

\begin{tabular}{|l|l|l|l|l|}
\hline Renita Wialectus & Ano 9 & n. 17 & Maio - Agosto 2020 & p.82-95 \\
\hline
\end{tabular}


docentes, pedagogos e planificadores. Não vou me referir à dificuldade de formulá-la, pois é óbvia, já que decorre da crise da ideia de escola. Baste lembrar que os atuais recursos de autoeducação parecem tornar obsoleto o papel do mestre, e que o livro, artefato chave da educação tradicional, parece fadado a desaparecer. ${ }^{25}$ Também, que a quantidade quase infinita de informação que podemos acessar (ou nos é impingida) torna difícil convertê-la em conhecimento ou em interpretações que façam sentido.

Ocorre que a própria noção de formação evoca, pela sua etimologia, uma meta rígida ou estável: adequar a uma forma. Nada menos apropriado a tempos em que tudo é "líquido" (Z. Bauman). Como pensar o objetivo da educação sem essa fixidez?

Escreve Yuval N. Harari:

Então, o que deveríamos estar ensinando? Muitos especialistas em pedagogia alegam que as escolas deveriam passar a ensinar "os quatro Cs" pensamento crítico, comunicação, colaboração e criatividade. Num sentido mais amplo, as escolas deveriam minimizar habilidades técnicas e enfatizar habilidades para propósitos genéricos na vida. O mais importante de tudo será a habilidade de lidar com mudanças, aprender coisas novas e preservar seu equilíbrio mental em situações que não lhe são familiares. Para poder acompanhar o mundo de 2050, você vai precisar inventar não só novas ideias e produtos - acima de tudo vai precisar inventar você mesmo várias e várias vezes (HARARI, 2018, p. 323). ${ }^{26}$

E acrescenta:

Para viver e progredir num mundo assim [de mudanças constantes e incertezas] você vai precisar de muita flexibilidade mental e de grandes reservas de equilíbrio emocional. Terá que abrir mão daquilo que sabe melhor e sentir-se à vontade com o que não sabe (HARARI, 2018, p. 327).

Gostei das propostas de Harari, que aconselha "abraçar o desconhecido" e manter o equilíbrio emocional que menciona na citação acima, ao que eu acrescentaria procurar decidir por si próprio o rumo da vida, como cerne de uma nova educação. ${ }^{27}$ Informações e habilidades seriam secundárias, variáveis, funcionais. Precisamos também perceber e enfrentar os problemas emanados do desenvolvimento tecnológico como um desafio coletivo que exige atitudes igualmente coletivas, ou melhor,

25 Não me refiro à substituição do livro de papel pelo e-book (que pode ser vista como apenas uma mudança de suporte), mas ao fato de estar sendo muito mais utilizados textos avulsos, em vez de compêndios. A aceleração do avanço de conhecimentos o explica parcialmente.

26 O autor alude à extinção crescente de empregos e profissões.

27 Harari mantém a importância do "conhece a ti mesmo", porém na forma de saber da constante e crescente manipulação a que estamos submetidos (HARARI, 2018:229).

\begin{tabular}{|c|c|c|c|c|}
\hline Revista Aialectus & Ano 9 & n. 17 & Maio - Agosto 2020 & p.82-95 \\
\hline
\end{tabular}


comunitárias. A sensibilidade para tanto deveria estar incluída em uma educação repensada. Ninguém se salva sozinho.

Mas essa educação não há de surgir do nada. Harari reconhece que os atuais professores, produtos que são da educação tradicional, não podem propiciá-la. Como transmissores de informação (se isso ainda for uma tarefa pedagógica) os docentes perdem rapidamente espaço como fontes privilegiadas. A auto-informação (com todos seus riscos) é possibilitada e estimulada pela tecnologia. E a própria noção de alguém que "ensina" outrem parece ultrapassada no mundo tecnológico, a não ser que "ensinar" seja sinônimo de ajudar a adquirir uma habilidade (como a de usar determinada tecnologia). Talvez estejamos nos encaminhando para uma sociedade em que desaparecerá a diferença entre educandos e educadores, bem como entre educação informal e formal.

Ao término do capítulo de (CUPANI, 2017), em que me referi aos impactos da tecnologia nas culturas, alertei o leitor ou leitora sobre o risco de julgar a tecnologia sem consciência do ponto de vista do crítico (ou do admirador). Boa parte dos perigos ou consequências negativas atribuídas à tecnologia provem, certamente, de pensadores educados na tradição humanista ocidental, assim como os entusiastas costumam ter formação científica ou tecnológica. ${ }^{28}$ Sugeri a comparação da vida na sociedade tecnológica coma de outras épocas e civilizações, pois muitas atitudes que parecem exclusivas da contemporaneidade talvez não o sejam (por exemplo, a aceitação acrítica da cultura material e simbólica). E fiz também menção da necessidade de não se deixar impressionar pelas aparências: muito do que se atribui à índole da tecnologia provavelmente responde à índole do capitalismo (afinal, a capitalista é a única tecnologia que conhecemos), ou a tendências da condição humana, caso ela exista. Seja como for, aconselho a leitura daquelas páginas (op.cit.: 198:200).

Por outra parte, o presente texto foi redigido antes da pandemia que assola a humanidade. Ninguém sabe, sequer conjectura, as características do mundo quando esta catástrofe passar. Uma coisa ficou comprovada: a ciência e a tecnologia não fizeram com que dominemos a Natureza, apesar do triunfalismo da civilização industrial desde o

28 De onde a diferença entre a Filosofia da ciência dos "humanistas" e dos "engenheiros" de C. Mitcham (MITCHAM 1994).

\begin{tabular}{|c|c|c|c|c|}
\hline Revita Didectus & Ano 9 & n. 17 & Maio - Agosto 2020 & p.82-95 \\
\hline
\end{tabular}


século XIX. ${ }^{29}$ Um vírus ínfimo colocou em xeque a vida humana e suas produções, incluída a tecnologia. Não está dentro do poder da ciência nem da tecnologia dizer o que deveria ser feito, em termos morais e políticos, quando este pesadelo terminar. A ciência diz respeito ao que é, e ao que pode ser racionalmente previsto. A tecnologia, ao que é factível, dado determinado objetivo. Nenhuma delas entende do que deva ser, embora possam fornecer recursos para alcançar aquilo que devemos fazer. A epidemia universal (como era, talvez, de se esperar) descortinou o melhor e o pior das atitudes humanas, do egoísmo à solidariedade, do temor irracional ao heroísmo, do protagonismo desvairado ao humilde comprimento da tarefa salvadora. Não sei se os filósofos (e os aspirantes a tais) estamos melhor capacitados do que o homem comum para propor novos critérios de vida, individual e coletiva. Quiçá já o fizeram os pensadores clássicos toda vez que falaram sobre o bem comum e sobre o amor à Natureza, sobre justiça social e desenvolvimento sustentável. Faltará pôr essas ideias em prática, sobretudo por parte dos detentores do poder.

\section{Referências:}

BODEN, M.A. Artificial intelligence: a very short introduction. Oxford: Oxford University Press, 2018[2016].

BORGMANN, A. Technology and the character of contemporary life: a philosophical inquiry. Chicago: University of Chicago Press, 1984.

BOSTROM, N. Superinteligência. Caminhos, perigos e estratégias para um mundo novo. (Superintelligence: Paths, Dangers, Strategies, trad. de A.A. Monteiro e outros). Rio de Janeiro, Dark Side Books, 2018 [2014].

BRONCANO, F. Mundos artificiales: Filosofía del cambio tecnológico. México: ed. UNAM-Paidós, 2000.

BUNGE, M. Epistemologia. São Paulo: T. A. Queiroz editor, 1980.

Matéria e mente. Uma investigação filosófica. (Matter and Mind: a philosophical investigation, trad. de G.K. Guinsburg). São Paulo: ed. Perspectiva, 2017.

CLARK, A. Natural-Born Cyborgs. Minds, Technologies, and the Future of Human Intelligence. New York: Oxford, 2003.

CUPANI, A. A realidade complexa da tecnologia. Cadernos IHU ideias. Ano 12, n. 216, vol. 12. São Leopoldo, RS: UNISINOS, 2014.

${ }^{29}$ Vale lembrar o alerta do livro, já clássico, de William Leiss (LEISS 1994 [1972]) sobre essa pretensão.

\begin{tabular}{|l|l|l|l|l|}
\hline Rovista Dialectus & Ano 9 & n. 17 & Maio - Agosto 2020 & p.82-95 \\
\hline
\end{tabular}


2017.

Filosofia da Tecnologia. Um convite. $3^{\mathrm{a}}$ ed. Florianópolis, Ed. Da UFSC,

DREYFUS H.L. What computers still can't do: a critique of artificial reason. Cambridge, Mass: The MIT Press, 1992.

FERRÉ, F. Philosophy of Technology. Athens/London, University of Georgia Press, 1995[1988].

HARARI, Y.N. 21 lições para o século 21 (21 Lessons for the 21 st Century, trad. de P. Geiger). São Paulo: Companhia das Letras, 2018.

IHDE, D. Tecnologia e mundo da vida: do jardim à terra. (Technology and the lifeworld. From garden to Earth, 1990, trad.de M.F. Bozatski). Chapecó: ed. UFFS, 2017.

LEISS, W. The Domination of Nature. Montreal \& Kingston: McGill-Queen's University Press, 1994 [1972].

MITCHAM, C. Thinking through Technology. The Path between Engineering and Philosophy. Chicago/London: The University of Chicago Press, 1994.

NUSSBAUM, M. Creating Capabilities. The Human Development Approach. Cambridge/London: The Belknap Press, 2011.

ORTEGA Y GASSET, J. Meditación de la Técnica. Madrid: Espasa Calpe, 1965 (orig. 1939).

PACEY, A. The culture of technology. Cambridge, Mass.: The MIT Press, 1994 [1983].

POSTMAN, N. Technopoly: the surrender of culture to technology. New York: Vintage, 1993.

SEARLE, J. Minds, brains and programs. Behavioral and Brain Sciences, 3(3):417424, 1980.

SEN, A. Desenvolvimento como liberdade. (Development as freedom, 1999, trad. L. T. Motta). São Paulo: Companhia das Letras, 2010.

SIMONDON, G. Du mode d'existence des objets techniques (orig. 1958). Paris: Aubier, 1989.

WINNER, L. Autonomous technology: technics-out-of-control as a theme in political thought. Cambridge: The MIT Press, 1977.

\begin{tabular}{|c|c|c|c|c|}
\hline Rovista Dialectus & Ano 9 & n. 17 & Maio - Agosto 2020 & p.82-95 \\
\hline
\end{tabular}

